Article

\title{
Transcriptomic Analysis of the Porcine Endometrium during Embryo Implantation
}

\author{
Haichao Lin ${ }^{1,2}$, Huaizhong Wang ${ }^{1}$, Yanping Wang ${ }^{1,2}$, Chang Liu ${ }^{1,2}$, Cheng Wang ${ }^{1}$ \\ and Jianfeng Guo ${ }^{1,2, *}$
}

1 Institute of Animal Science and Veterinary Medicine, Shandong Academy of Agricultural Sciences, Jinan 250100, China; E-Mails: marslhc@126.com (H.L.); whzh0825@163.com (H.W.); wangyanping03@163.com (Y.W.); liuchangjlau16@126.com (C.L.); jinanwangcheng@163.com (C.W.)

2 Key Laboratory of Disease Control and Animal Breeding of Shandong Province, Jinan 250100, China

* Author to whom correspondence should be addressed; E-Mail: guojf982@163.com; Tel.: +86-531-8897-8796; Fax: +86-531-8861-3698.

Academic Editor: Montserrat Corominas

Received: 6 October 2015 / Accepted: 4 December 2015 / Published: 21 December 2015

\begin{abstract}
In pigs, successful embryo implantation is an important guarantee for producing litter size, and early embryonic loss occurring on day 12-30 of gestation critically affects the potential litter size. The implantation process is regulated by the expression of numerous genes, so comprehensive analysis of the endometrium is necessary. In this study, RNA sequencing (RNA-Seq) technology is used to analyze endometrial tissues during early pregnancy. We investigated the changes of gene expression between three stages (day 12,18 , and 25) by multiple comparisons. There were 1557, 8951, and 2345 differentially expressed genes (DEGs) revealed between the different periods of implantation. We selected several genes for validation by the use of quantitative real-time RT-PCR. Bioinformatic analysis of differentially expressed genes in the endometrium revealed a number of biological processes and pathways potentially involved in embryo implantation in the pig, most noticeably cell proliferation, regulation of immune response, interaction of cytokine-cytokine receptors, and cell adhesion. These results showed that specific gene expression patterns reflect the different functions of the endometrium in three stages (maternal recognition, conceptus attachment, and embryo implantation). This study identified comprehensive transcriptomic profile in the porcine endometrium and thus could
\end{abstract}


be a foundation for targeted studies of genes and pathways potentially involved in abnormal endometrial receptivity and embryo loss in early pregnancy.

Keywords: embryo implantation; endometrium; pigs; pregnancy; sows; transcriptome

\section{Introduction}

Endometrial receptivity is critical for the establishment of successful implantation; this depends on a highly coordinated process involving changes in hormones, cytokines, adhesion molecules, enzymes, and growth factors $[1,2]$. In mammals, including pigs, the endometrium undergoes a transformation in response to the physiological changes triggered by ovarian hormones in different stages of the cycle to prepare for embryo attachment and implantation [3]. Early pregnancy in pigs is followed by a dynamic production of estrogens, prostaglandins, adhesion molecules, and immunological factors. Porcine embryos produce large amounts of estrogens, which enhance endometrial PGE2 production around days 11-12 of pregnancy, the period of maternal recognition of pregnancy [4,5]. With the trophoblast, rapid elongation and migration in the uterus, apposition, and attachment to the uterine surface epithelium occurs on days 16-18, initiating epitheliochorial placentation [6]. During the pre-attachment period, conceptuses undergo differentiation of trophectoderm for the secretion of an antiluteolytic or luteotrophic pregnancy recognition signal for maintenance of functional corpus luteum.

Litter size is one of the most economically important traits in pig production. However, reproductive traits in pigs are complex; from ovulation, fertilization, and implantation through to the birth of piglets, every step may affect litter size. Of these steps, implantation is the most important, since most embryonic deaths take place in this period. Approximately $45 \%$ of embryos for Large White and 21\% for Meishan are lost between days 12 and 30 of pregnancy [7]. Periodic expression of many genes important for embryos occurs during implantation. Their proper and synchronized expression is essential for embryo survival and development. Systematic studies of transcriptome changes in the porcine endometrium during the time of implantation days 12, 14 [8-10], and days 15-16 [11] have been performed with DNA microarrays or RNA sequencing (RNA-Seq). However, transcriptomic analysis of the porcine endometrium during the whole implantation phase has not been performed. In this study, we use RNA-Seq to analyze the responses of the porcine endometrium to conceptus signals on day 12 (the time of maternal recognition), day 18 (conceptus attachment), and day 25 (embryo implantation) of pregnancy.

\section{Experimental Section}

\subsection{Animals and Tissue Collection}

Estrous behavior of sows was observed on every day. Sows exhibiting at least two estrous cycles of normal duration (21 days) were assigned randomly to three groups. Estrus occurred $24 \mathrm{~h}$ later (day 0), and the animals were inseminated twice with an interval of about $12 \mathrm{~h}$. Nine sows were slaughtered at different stages of early pregnancy by electrical stunning: day $12(n=3)$, day $18(n=3)$, and day 25 $(n=3)$. The uteri were removed, and each uterine horn was subsequently flushed first with $10 \mathrm{~mL}$ and 
then with $50 \mathrm{~mL}$ of PBS buffer to collect conceptuses and uterine fluid. After flushing, uterine horns were opened longitudinally at the antimesometrial side. Several sections of the endometrium (not including the myometrium) were taken from the middle portion of the uterine horn of each sow on day 12. The samples of endometrium (peel off embryo) in attachment site (day 18) and implantation site (day 25) were collected. All tissue samples for isolation of RNA were immediately transferred to RNAlater (Invitrogen), incubated overnight at $4{ }^{\circ} \mathrm{C}$, and stored at $-80{ }^{\circ} \mathrm{C}$ until further use.

All experiments were approved by the Animal Ethics Committee, Shandong Academy of Agricultural Sciences, Jinan, China.

\section{2. mRNA Library Construction and Sequencing}

Total RNA was extracted using Trizol reagent (Invitrogen, Carlsbad, CA, USA) following the manufacturer's procedures. The total RNA quantity and purity were analysis of Bioanalyzer 2100 and RNA 6000 Nano LabChip Kit (Agilent, Santa Clara, CA, USA) with RIN number > 8.0. Approximately $10 \mu \mathrm{g}$ of total RNA representing a specific adipose type was subjected to isolate Poly (A) mRNA with poly-T oligo attached magnetic beads (Invitrogen).

Following purification, the mRNA is fragmented into small pieces using divalent cations under elevated temperature. Then the cleaved RNA fragments were reverse-transcribed to create the final cDNA library in accordance with the protocol for the mRNA-Seq sample preparation kit (Illumina, San Diego, CA, USA); the average insert size for the paired-end libraries was $300 \mathrm{bp}$ ( $\pm 50 \mathrm{bp}$ ). Next we performed the paired-end sequencing on an Illumina Hiseq2000 at the LC-BIO (Hangzhou, China) following the vendor's recommended protocol.

\subsection{RNA-Seq Data Analysis}

For each sample, sequenced reads were aligned to the UCSC [12] pig reference genome using the Tophat package, which initially removes a portion of the reads based on quality information accompanying each read and then maps the reads to the reference genome. Tophat allows multiple alignments per read (up to 20 by default) and a maximum of two mismatches when mapping the reads to the reference. Tophat builds a database of potential splice junctions and confirms these by comparing the previously unmapped reads against the database of putative junctions. The raw sequence data have been submitted to the NCBI Short Read Archive with accession number GSE73695.

\subsection{Transcript Abundance Estimation and Differentially Expressed Testing}

The aligned read files were processed by Cufflinks, which uses the normalized RNA-seq fragments counts to measure the relative abundances of the transcripts. The unit of measurement is Fragment Per Kilobase of exon per Million fragments mapped (FPKM). The reference GTF annotation file used in Cufflinks was downloaded from the UCSC database. Cufflink was used to de novo assemble the transcriptome at first; next, Cuffmerge was used to merge all transcripts of sample A and B to generate unique transcripts. The downloaded UCSC GTF file was passed to Cuffdiff along with the original alignment (SAM) files produced by Tophat. Cuffdiff re-estimates the abundance of the transcripts listed in the GTF file using alignments from the SAM file and concurrently tests for different 
expression. Only the comparisons with q value less than 0.01 and status marked as " $\mathrm{OK}$ " in the Cuffdiff output were regarded as showing differential expression.

\subsection{Functional Enrichment Analysis}

Assembled transcripts were converted to human orthologous genes, and the lists were submitted to the DAVID [13] web server [14] for enrichment analysis of the significant overrepresentation of GO biological processes (GO-BP), molecular function (GO-MF) terminologies, and KEGG-pathway category. In all tests, completely known genes were appointed as the background, and P-values (i.e., EASE score), indicating significance of the overlap between various gene sets, were calculated using Benjamini-corrected modified Fisher's exact test. Only GO-BP, GO-MF, or KEGG-pathway terms with a P-value less than 0.05 were considered significant and listed.

\subsection{Quantitative Real-Time PCR}

Quantitative RT-PCR (q-PCR) was used to measure the mRNA expression levels of eight representative indicators. Quantitative real-time PCR was performed on a Roche LightCycler ${ }^{\circledR} 480$ instrument (Roche, Penzberg, Germany) using SYBR ${ }^{\circledR}$ Green Real-time PCR Master Mix (TaKaRa, Dalian, China). The total RNA samples used for qRT-PCR analyses are the same as the RNA-Seq acquired from the same nine sows. The PCR primer sequences are shown in Table 1. Gene expression levels were calculated using the $\Delta \Delta \mathrm{Ct}$ method and normalized using the geometric mean of expression levels of porcine ACTB and RN18S. The statistical difference in gene expression between the endometrium from different implantation periods was analyzed by t-test. Confirmed differences in gene expression were expressed as fold changes.

Table 1. Primer sequences for quantitative real-time RT-PCR.

\begin{tabular}{lllll}
\hline $\begin{array}{l}\text { Gene } \\
\text { Symbol }\end{array}$ & \multicolumn{1}{c}{ Gene Name } & & \multicolumn{1}{c}{ Primer Sequence } & $\begin{array}{c}\text { Target Accession } \\
\text { No. }\end{array}$ \\
\hline ACTB & actin, beta & F: & CGAGCGCTTCCGGTGTCCAG & XM_003357928.1 \\
& & R: & GTGGTCCCGCCAGACAGCAC & \\
RN18S & 18S ribosomal RNA & F: & GGGAGGAGGCTGACCGGGTT & NR_002170.3 \\
& & R: & ATACATGCCGACGGGCGCTG & \\
FGF9 & fibroblast growth factor & F: & TTCCCAGGGGACCCGCAGTC & NM_213801.1 \\
& 9 (glia-activating factor) & R: & ATGCTGACCAAGCCCACGGC & \\
IRF1 & interferon regulatory & F: & CCTTGTGCACCGTAGGCGGG & NM_001097413.1 \\
& factor 1 & R: & GGCTTGCCAGGCCCCAGAG & \\
PTGES & prostaglandin E synthase & F: & TGGTGAGCGGCCAGGTT & NM_001038631.1 \\
& & R: & TGGCCACTACGTACATCTTGATG & \\
OSTN & osteocrin & F: & CCCCTGGACAGACTCTCAGCAGG & NM_001098597.1 \\
& & R: & GCCTCTGGAATTGGAAGCCGGT & \\
S100A9 & S100 calcium binding & F: & ACCACATCCTGGAAGACCTG & NM_001177906.1 \\
& protein A9 & R: & TCCTCGTGAGAAGCTACCGT & \\
\hline
\end{tabular}


Table 1. Cont.

\begin{tabular}{lllll}
\hline $\begin{array}{l}\text { Gene } \\
\text { Symbol }\end{array}$ & \multicolumn{1}{c}{ Gene Name } & & \multicolumn{1}{c}{ Primer Sequence } & $\begin{array}{c}\text { Target Accession } \\
\text { No. }\end{array}$ \\
\hline STAT1 & $\begin{array}{l}\text { signal transducer and } \\
\text { activator of transcription } \\
\end{array}$ & F: & AAATGCCGGCGCCAGAACCA & NM_213769.1 \\
1,91 kDa & CGGGAGCTGGCTGACGTTGG & \\
Stanniocalcin 1 & F: & ACACGCACCAGCGAGCTGAC & NM_001103212.1 \\
& & R: & GCTGTGAACACCTCGCCCCC & \\
\hline
\end{tabular}

\section{Results}

\subsection{RNA-Seq Data for the Endometrium on Days 12, 18, and 25 of Pregnancy}

From $34,275,994$ to $124,850,826$ raw reads and from $33,688,562$ to $122,914,990$ quality-filtered reads were found per sample. Using the Tophat package [15], 55.84\%-77.99\% reads were mapped ( $<2$ mismatches) to the UCSC pig reference genome, $51.42 \%-72.25 \%$ reads had a unique genomic location (Table 2). Then, Cufflinks [16] was used to de novo assemble the porcine endometrium transcriptome, 45,828 transcripts were assembled and 20,310 genes were named in the UCSC pig genome database.

Table 2. Summary of RNA-Seq alignment.

\begin{tabular}{lccccccc}
\hline Sample & $\begin{array}{c}\text { Raw } \\
\text { Reads }\end{array}$ & $\begin{array}{c}\text { Clean } \\
\text { Reads }\end{array}$ & $\begin{array}{c}\text { Clean } \\
\text { Data }\end{array}$ & $\begin{array}{c}\text { Mapped } \\
\text { Reads }\end{array}$ & $\begin{array}{c}\text { Unique } \\
\text { Mapped } \\
\text { Reads }\end{array}$ & $\begin{array}{c}\text { Multi } \\
\text { Mapped } \\
\text { Reads }\end{array}$ & $\begin{array}{c}\text { Pair-End } \\
\text { Mapped } \\
\text { Reads }\end{array}$ \\
\hline D12-01 & 67169826 & 66077622 & 66077622 & 49833482 & 46142686 & 3690796 & 23127536 \\
D12-02 & 41784360 & 39324942 & 39324942 & 29499855 & 27337499 & 2162356 & 13706839 \\
D12-03 & 34275994 & 33688562 & 33688562 & 25394236 & 23553198 & 1841038 & 11998456 \\
D18-01 & 41684596 & 40824568 & 40824568 & 26668182 & 24658656 & 2009526 & 12636036 \\
D18-02 & 40426950 & 39987798 & 39987798 & 22327827 & 20562051 & 1765776 & 10550537 \\
D18-03 & 44795678 & 44415892 & 44415892 & 28210350 & 26213892 & 1996458 & 13001074 \\
D25-01 & 50047464 & 49009334 & 49009334 & 37099086 & 33754041 & 3345045 & 17284406 \\
D25-02 & 84890198 & 83601216 & 83601216 & 64826626 & 57999868 & 6826758 & 30054104 \\
D25-03 & 124850826 & 122914990 & 122914990 & 95857938 & 88801603 & 7056335 & 43719905 \\
\hline
\end{tabular}

The RNA-Seq alignment is similar to all samples collected from the endometrium on day 18 of pregnancy. However, the alignment is quite variable between samples collected on day 12 and day 24 of pregnancy. This kind of variability is possibly the result of different sampling sites or implantation of the endometrium. On day 12 of pregnancy, the samples of endometrium were taken from the antimesometrial side and the middle portion of each uterine horn of each sow; there may be a difference between the sampling sites of different pigs due to the embryo not having attached to the uterine wall, and the RNA-seq alignment was variable in this stage. Because the conceptus attachment arises from about day 18 of pregnancy, the status of the endometrium (attachment site) is similar. However, the time of implantation of a fertilized egg may be different due to the diversity among 
conceptuses, and this results in differences in the samples collected on day 25. Therefore, there is more variability of RNA-seq alignment on day 25 than on day 18 of pregnancy (Figure 1).
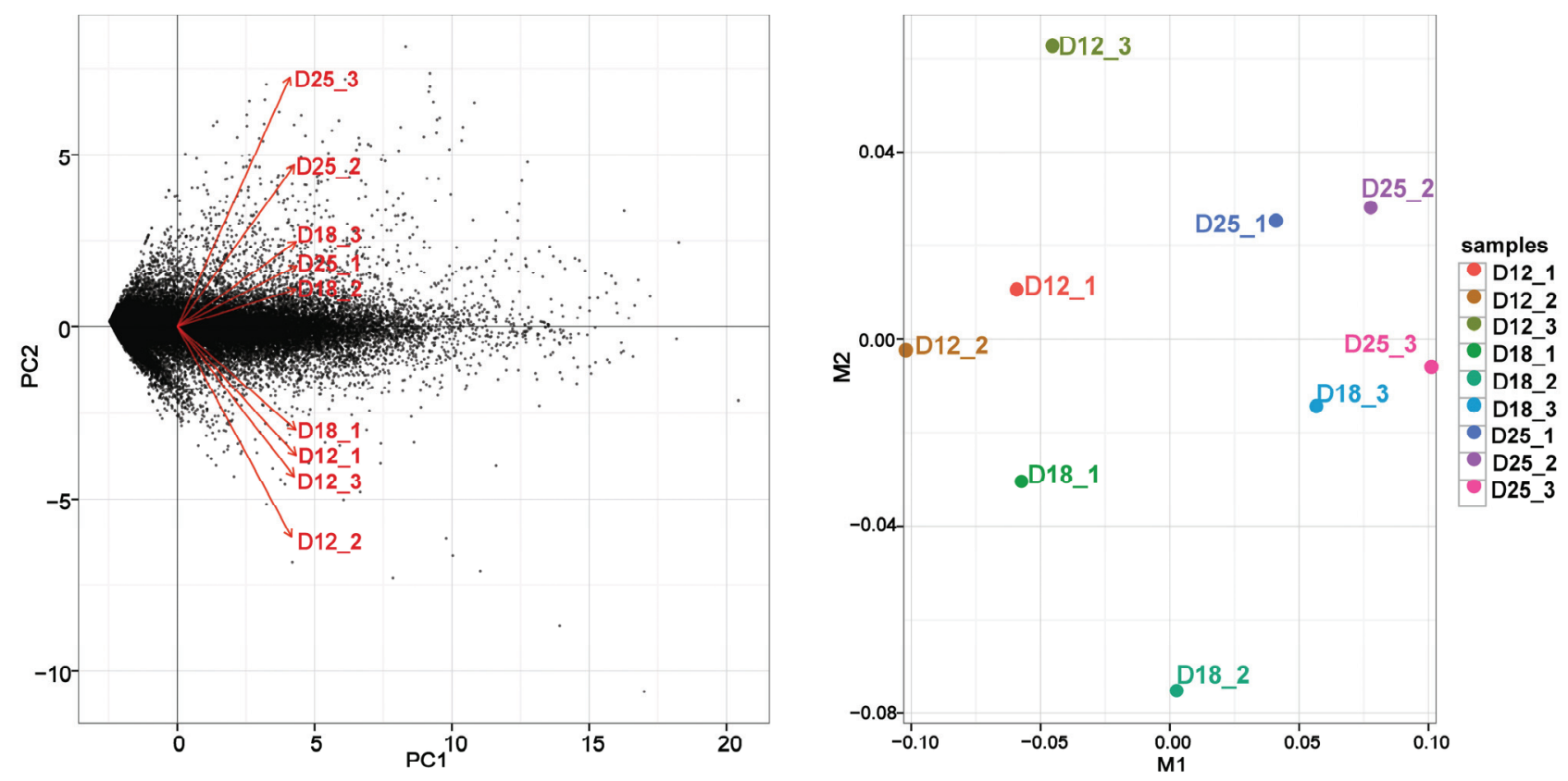

Figure 1. Principal component analysis (PCA) and multidimensional scaling (MDS) results of RNA-Seq data of endometrium on days 12, 18, and 25 of pregnancy.

\subsection{Gene Expression Variations between the Different Implantation Stages}

FPKM of each gene was processed by Cufflinks, and Cuffmerge was used to merge all transcripts of sample A and B to generate unique transcripts. To identify the differentially expressed genes during different implantation stages, the comparisons were analyzed between day 12 and 18, day 18 and 25, and day 12 and 25, respectively. The amount of differentially expressed genes (DEGs) between day 12 and 25 was the most (8951 differentially expressed genes), followed by between day 18 and 25 (Table 3). A total of 188 transcripts were expressed differentially among the three stages of pregnancy (Figure 2), of which 60 genes were upregulated (i.e., DPPA5, OSTN, PPARG, TIMP1, etc.) and 38 genes downregulated with the stage (i.e., STC1, SATB1, etc.). Sixty-four of these were significantly increased on day 18 with regard to days 12 and 25 (i.e., FETUB, IFNG, ITGB2, ITGA4, etc.), and 26 were significantly decreased on day 18 compared with days 12 and 25 (i.e., SELL, MMP7, etc.).

Table 3. Differentially expressed genes (DEGs) of the endometrium in the three periods of pregnancy.

\begin{tabular}{ccccc}
\hline Sample & TB Gene Number & DEGs & Upregulation & Downregulation \\
\hline D12 vs. D18 & & 1557 & 708 & 849 \\
D12 vs. D25 & 45828 & 8951 & 4999 & 3952 \\
D18 vs. D25 & & 2345 & 1166 & 1179 \\
\hline
\end{tabular}




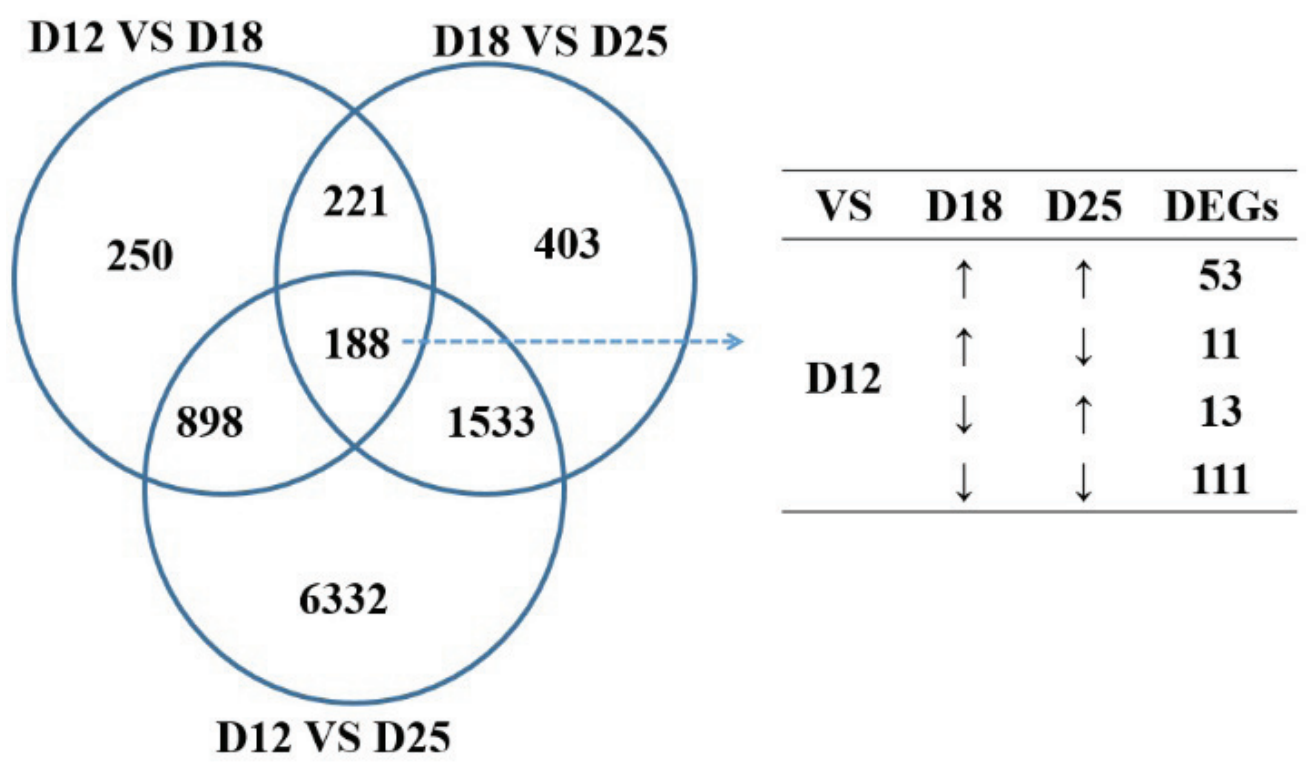

Figure 2. Differentially expressed genes (DEGs) of the endometrium for the three periods of pregnancy.

\subsection{Gene Ontology (GO) and Genomes (KEGG) Ontology (KO) Classification (Up Arrow Indicates Upregulation, and Down Arrow Indicates Downregulation)}

There are significant differences in expression between days 12 and 18 of pregnancy. A total of 1557 genes, of which 708 were upregulated and 849 downregulated, were identified on day 12 vs. 18. According to the GO enrichment analyses, in the category of molecular function (MF), the most genes clustered in "protein binding" (Figure 3). In the category of biological process (BP), the DEGs clustered in "transport", "regulation of transcription, DNA-dependent" "oxidation-reduction process", "signal transduction", etc. In the category of cellular components, the differentially expressed genes were mainly related to "membrane", "cytoplasm", "nucleus", and "integral to membrane".

A total of 8951 and 2345 genes were differentially expressed in the endometrium between D12 vs. D18 and D18 vs. 25 (Table 3), respectively. As a comparison between D12 vs. D18, the most genes between D12 vs. D25 and D18 vs. D25 were related to "protein binding" in the category of MF. On the other hand, the DEGs clustered in "transport", "regulation of transcription, DNA-dependent", and "signal transduction" are in the category of BP.

The biological pathways of significant DEGs in different periods of implantation are shown in Table 4. According to the KEGG database, the most significant DEGs between day 12 and 18, and day 18 and 25, were clustered in the "cytokine-cytokine receptor interaction", "complement and coagulation cascades", and "focal adhesion" pathways. The DEGs between day 12 and 25 were enriched in the "protein processing in endoplasmic reticulum", "cell cycle", "oxidative phosphorylation", "phagosome", "ribosome biogenesis in eukaryotes", "axon guidance", "Wnt signaling", "focal adhesion", and "complement and coagulation cascades" pathways, etc. 

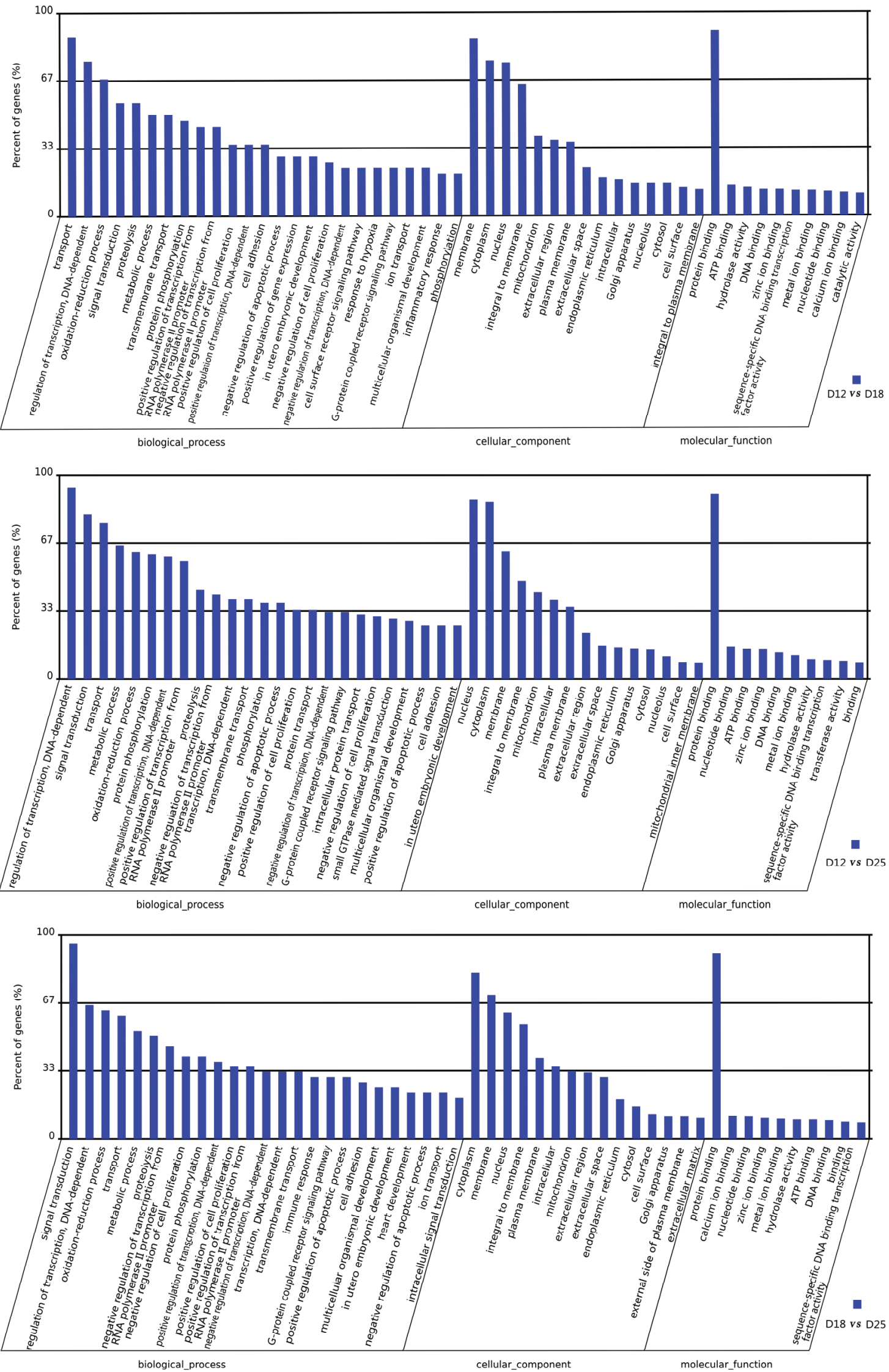

Figure 3. GO categories of the transcripts expressed differently between the three periods (days 12, 18, and 25) of pregnancy. Transcripts were annotated in three categories: cellular components, molecular functions, and biological processes. 
Table 4. The most significant DEGs biological pathways examined with the KEGG database $(p \leq 0.01)$.

\begin{tabular}{|c|c|c|c|c|c|c|}
\hline & & $\begin{array}{c}\text { Pathway } \\
\text { ID }\end{array}$ & Pathway Name & $\begin{array}{c}\text { Gene } \\
\text { Number }\end{array}$ & $p$-Value & Gene List * \\
\hline & 1. & $\operatorname{ssc} 04060$ & $\begin{array}{l}\text { Cytokine-cytokine } \\
\text { receptor interaction }\end{array}$ & 13 & $1.79 \times 10^{-4}$ & $\begin{array}{l}\text { ACVR1, ACVR1B, FIGF, MET, } \\
C C R 7, C S F 1 R, C S F 2 R B, \\
C X C L 14, C X C R 3, I F N G R 1, \\
I L 10 R A, I L 21 R, I L 2 R G\end{array}$ \\
\hline & 2. & $\operatorname{ssc} 04610$ & $\begin{array}{l}\text { Complement and } \\
\text { coagulation cascades }\end{array}$ & 10 & $2.26 \times 10^{-7}$ & $\begin{array}{l}\boldsymbol{C 7}, \boldsymbol{D F}, \boldsymbol{F 5}, C 1 Q A, C 2, C F H \\
F 10, F G B, K N G 1, P L A U R\end{array}$ \\
\hline & 3. & $\operatorname{ssc} 04510$ & Focal adhesion & 8 & $4.19 \times 10^{-5}$ & $\begin{array}{l}\text { COL5A3, ITGB8, COL11A1, } \\
\text { ITGA4, LAMA3, MYL7, PARVG, } \\
\text { SPP1 }\end{array}$ \\
\hline & 4. & $\operatorname{ssc} 04110$ & Cell cycle & 8 & $7.39 \times 10^{-4}$ & $\begin{array}{l}\text { CDKN2B, CDKN2B, PLS1, } \\
\text { SMAD2, CDC2, CDC6, SKP2, } \\
W E E 1\end{array}$ \\
\hline & 5. & $\operatorname{ssc} 00270$ & $\begin{array}{l}\text { Cysteine and } \\
\text { methionine } \\
\text { metabolism }\end{array}$ & 6 & $1.18 \times 10^{-6}$ & $\begin{array}{l}\text { CDO1, AHCY, AMD1, DNMT3B, } \\
\text { MAT1A, SMS }\end{array}$ \\
\hline & 6. & $\operatorname{ssc} 04142$ & Lysosome & 6 & $1.66 \times 10^{-3}$ & $\begin{array}{l}\text { AP1B1, CTSC, CTSH, CTSZ, } \\
\text { DNASE2, NPC2 }\end{array}$ \\
\hline & 7. & $\operatorname{ssc} 04360$ & Axon guidance & 6 & $4.97 \times 10^{-3}$ & $\begin{array}{l}\text { EFNA1, SEMA6A, EPHA2, } \\
S E M A 3 F, S E M A 4 A, U N C 5 B\end{array}$ \\
\hline $\begin{array}{c}\text { Day } 12 \\
\text { vs. }\end{array}$ & 8. & $\operatorname{ssc} 00190$ & $\begin{array}{l}\text { Oxidative } \\
\text { phosphorylation }\end{array}$ & 6 & $8.96 \times 10^{-3}$ & $\begin{array}{l}\text { ATP6V1C2, ATP5G1, } \\
\text { ATP6V1G3, NDUFA10, } \\
\text { NDUFS3, UQCRC1 }\end{array}$ \\
\hline \multirow[t]{10}{*}{ Day 18} & 9. & ssc04514 & $\begin{array}{l}\text { Cell adhesion } \\
\text { molecules (CAMs) }\end{array}$ & 6 & $8.96 \times 10^{-3}$ & $\begin{array}{l}\text { SELL }, C D 2, C D 4, C D 8 A, I T G A L, \\
\text { PTPRC }\end{array}$ \\
\hline & 10. & $\operatorname{ssc} 00860$ & $\begin{array}{l}\text { Porphyrin and } \\
\text { chlorophyll } \\
\text { metabolism }\end{array}$ & 5 & $6.97 \times 10^{-5}$ & $\boldsymbol{C P}, C P O X, E P R S, H M B S, U R O D$ \\
\hline & 11. & $\operatorname{ssc} 00512$ & $\begin{array}{l}\text { Mucin type O-Glycan } \\
\text { biosynthesis }\end{array}$ & 5 & $1.98 \times 10^{-4}$ & $\begin{array}{l}\text { GALNT11, GALNTL5, GCNT1, } \\
B 4 G A L T 5, G A L N T 9\end{array}$ \\
\hline & 12. & $\operatorname{ssc} 04115$ & $\begin{array}{l}\text { p53 signaling } \\
\text { pathway }\end{array}$ & 4 & $1.98 \times 10^{-4}$ & $\begin{array}{l}\text { SESN3, CYCS, GTSE1, } \\
\text { SERPINB5 }\end{array}$ \\
\hline & 13. & $\operatorname{ssc} 04650$ & $\begin{array}{l}\text { Natural killer cell } \\
\text { mediated cytotoxicity }\end{array}$ & 4 & $5.28 \times 10^{-4}$ & $C D 244, C D 48, F C E R 1 G, P R F 1$ \\
\hline & 14. & $\operatorname{ssc} 03320$ & $\begin{array}{l}\text { PPAR signaling } \\
\text { pathway }\end{array}$ & 4 & $5.00 \times 10^{-3}$ & CD36, APOA1, FABP5, PPARG \\
\hline & 15. & $\operatorname{ssc} 02010$ & $\mathrm{ABC}$ transporters & 4 & $5.95 \times 10^{-3}$ & $\begin{array}{l}\text { ABCA1, ABCB10, ABCC2, } \\
\text { CFTR }\end{array}$ \\
\hline & 16. & $\operatorname{ssc} 04614$ & $\begin{array}{l}\text { Renin-angiotensin } \\
\text { system }\end{array}$ & 3 & $1.88 \times 10^{-5}$ & ACE2, LNPEP, MME \\
\hline & 17. & $\operatorname{ssc} 04350$ & $\begin{array}{l}\text { TGF-beta signaling } \\
\text { pathway }\end{array}$ & 3 & $3.72 \times 10^{-4}$ & $\boldsymbol{F S T}, I D 1, I D 2$ \\
\hline & 18. & $\operatorname{ssc} 05010$ & Alzheimer's disease & 2 & $6.84 \times 10^{-3}$ & $A P O E, B A C E 2$ \\
\hline
\end{tabular}


Table 4. Cont.

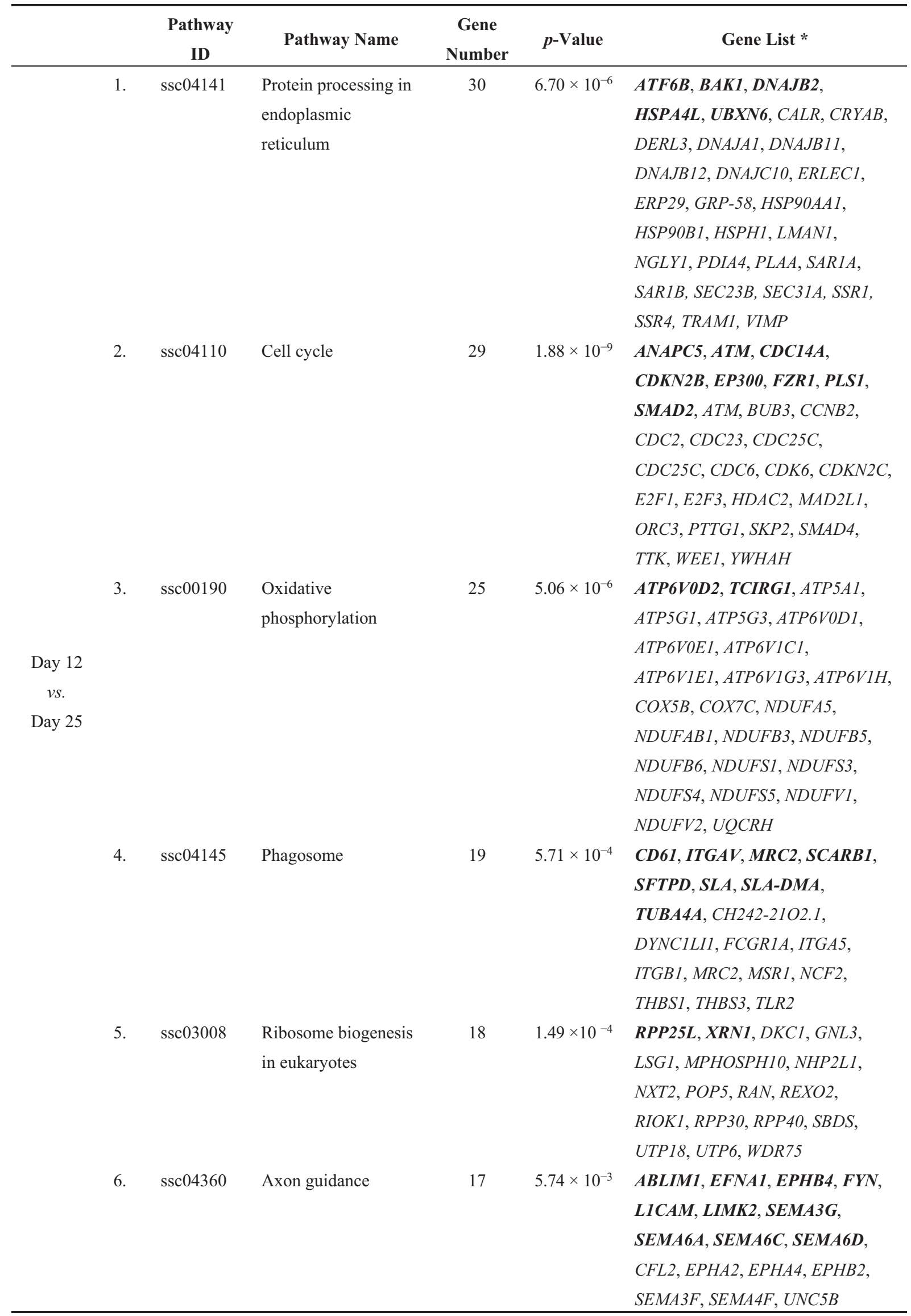


Table 4. Cont.

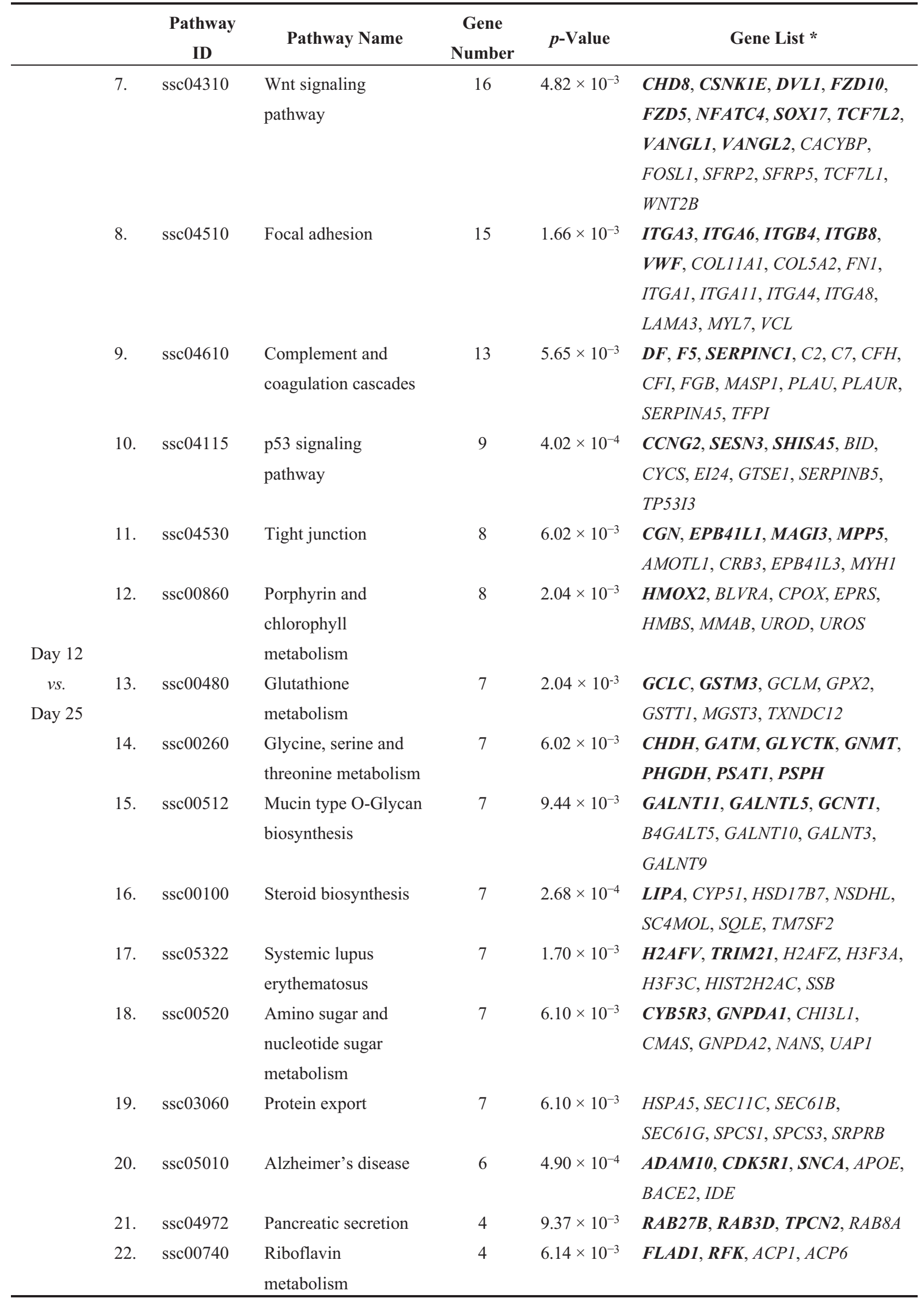


Table 4. Cont.

\begin{tabular}{|c|c|c|c|c|c|c|}
\hline & & $\begin{array}{c}\text { Pathway } \\
\text { ID }\end{array}$ & Pathway Name & $\begin{array}{c}\text { Gene } \\
\text { Number }\end{array}$ & $p$-Value & Gene List * \\
\hline \multirow{14}{*}{$\begin{array}{l}\text { Day } 18 \\
\text { vs. } \\
\text { Day } 25\end{array}$} & 1. & $\operatorname{ssc} 04060$ & $\begin{array}{l}\text { Cytokine-cytokine } \\
\text { receptor interaction }\end{array}$ & 19 & $7.75 \times 10^{-6}$ & $\begin{array}{l}\text { CCR7, CD27, CD40, CSF1R, } \\
\text { CXCL10, CXCL16, CXCR3, } \\
\text { FLT3LG, IFNE, IL10RA,IL21R, } \\
\text { IL2RG, LIFR, LTB, MET, } \\
\text { TNFRSF21, CSF3, IL13RA1, IL18 }\end{array}$ \\
\hline & 2. & $\operatorname{ssc} 04145$ & Phagosome & 13 & $3.31 \times 10^{-7}$ & $\begin{array}{l}\text { CD61, DMB, SLA, SLA-DMA, } \\
\text { TUBA4A, CD209, CH242-21O2.1, } \\
\text { ITGB1, MRC2, MSR1, THBS1, } \\
\text { THBS2, THBS3 }\end{array}$ \\
\hline & 3. & ssc00190 & $\begin{array}{l}\text { Oxidative } \\
\text { phosphorylation }\end{array}$ & 12 & $1.18 \times 10^{-5}$ & $\begin{array}{l}\text { ATP6VOC, ATP6VOD2, NDUFS6, } \\
\text { TCIRG1, ATP6V1C2, ATP6V1E1, } \\
\text { NDUFA5, NDUFB } 3, \text { NDUFB6, } \\
\text { NDUFS4, NDUFS5, NDUFV2 }\end{array}$ \\
\hline & 4. & $\operatorname{ssc} 04610$ & $\begin{array}{l}\text { Complement and } \\
\text { coagulation cascades }\end{array}$ & 11 & $1.12 \times 10^{-6}$ & $\begin{array}{l}\text { C1QA, C8G, DF, FGB, KNG1, } \\
\text { SERPINA1, SERPINA5, } \\
\text { SERPINC1, C7, CFH, CFI }\end{array}$ \\
\hline & 5. & $\operatorname{ssc} 04510$ & Focal adhesion & 10 & $1.96 \times 10^{-5}$ & $\begin{array}{l}\text { COL11A1, ITGA3, ITGA4, } \\
\text { LAMB3, PARVG, COL5A2, } \\
\text { ITGA11, ITGA8, MYL } 7, V C L\end{array}$ \\
\hline & 6. & $\operatorname{ssc} 04514$ & $\begin{array}{l}\text { Cell adhesion molecules } \\
\text { (CAMs) }\end{array}$ & 8 & $5.26 \times 10^{-3}$ & $\begin{array}{l}\text { CD8A, CLDN8, ITGAL, PTPRC, } \\
\text { PECAM1, SELL, VCAM1, VCAN }\end{array}$ \\
\hline & 7. & ssc00260 & $\begin{array}{l}\text { Glycine, serine, and } \\
\text { threonine metabolism }\end{array}$ & 5 & $9.15 \times 10^{-5}$ & $\begin{array}{l}\text { GLYCTK, GNMT, PHGDH, } \\
\text { PSAT1, AOC } 3\end{array}$ \\
\hline & 8. & $\operatorname{ssc} 03320$ & $\begin{array}{l}\text { PPAR signaling } \\
\text { pathway }\end{array}$ & 5 & $3.57 \times 10^{-3}$ & $\begin{array}{l}\text { APOA1, APOA2, APOC } 3 \\
\text { PPARD, PPARG }\end{array}$ \\
\hline & 9. & $\operatorname{ssc} 04270$ & $\begin{array}{l}\text { Vascular smooth muscle } \\
\text { contraction }\end{array}$ & 4 & $2.04 \times 10^{-4}$ & $\begin{array}{l}\text { ACTA2, CALD1, KCNMB1, } \\
\text { PPPIR12B }\end{array}$ \\
\hline & 10. & $\operatorname{ssc} 04650$ & $\begin{array}{l}\text { Natural killer cell- } \\
\text { mediated cytotoxicity }\end{array}$ & 4 & $2.43 \times 10^{-3}$ & CD3Z, CD48, PRF1, ZAP70 \\
\hline & 11. & $\operatorname{ssc} 00480$ & Glutathione metabolism & 4 & $4.53 \times 10^{-3}$ & GCLC, GCLM, GPX2, TXNDC12 \\
\hline & 12. & $\operatorname{ssc} 00590$ & $\begin{array}{l}\text { Arachidonic acid } \\
\text { metabolism }\end{array}$ & 4 & $7.58 \times 10^{-3}$ & $\begin{array}{l}\text { ALOX12, ALOX15B, LTA4H, } \\
\text { PTGIS }\end{array}$ \\
\hline & 13. & ssc00340 & Histidine metabolism & 3 & $4.01 \times 10^{-3}$ & HAL, HDC, UROCI \\
\hline & 14. & $\operatorname{ssc} 00100$ & Steroid biosynthesis & 3 & $8.91 \times 10^{-3}$ & CYP51, HSD17B7, SC4MOL \\
\hline
\end{tabular}

* Upregulated genes are marked by bold font and downregulated genes are marked by regular font.

Three genes (CDKN2B, ATM, and CDC25C) are duplicated in Table 4. CDKN2B is in bold (upregulated) and included twice as a DEG in the cell cycle pathway of day $12 \mathrm{vs}$. day 18 of pregnancy; this is because alternative splicing events happen in this gene location (chr1:223955644223965842), and these two alternative transcriptions of CDKN2B are DEG on day 12 and day 18. In the same way, the gene $\mathrm{CDC} 25 \mathrm{C}$ is in regular font (downregulated) and included twice as a DEG in the cell cycle pathway of day 12 vs. day 25 of pregnancy (alternative splicing on chr2:145985624146023775). However, the gene ATM is in both bold and regular font (Table 4) when comparing 
DEGs obtained from endometrium on day 12 vs. day 25; two variable transcripts (chr9:4092589440945439 and 40746502-40833540) are present in different expression patterns, the transcript of ATM chr9:40925894-40945439 upregulated and chr9:40746502-40833540 downregulated on day 25 as compared to day 12.

\subsection{Validation of the RNA-Seq Data}

To validate the RNA-Seq data, eight genes were selected for q-PCR. The samples used for qRT-PCR analyses are the same as RNA-Seq; they were acquired from the same nine sows and thus result in a good agreement between the two techniques, as shown in Table 5. As mentioned in the results (Section 3.1), the RNA-seq data are quite variable between samples collected on days 12 and 24 of pregnancy. This kind of variability is possibly the result of different sampling sites or implantation of the endometrium. Therefore biologically reproducible studies are necessary to more accurate results. The genes selected for real-time PCR (Table 3) are involved in the following aspects of the regulation of early pregnancy: fibroblast growth (FGF9), immune response (IRF1), adhesion (OSTN), prostaglandin synthase (PTGES), signal transducer and activator of transcription (STAT1), and implantation marker (STC1).

Table 5. Results of selected gene expression validation with quantitative real-time PCR.

\begin{tabular}{|c|c|c|c|c|c|c|}
\hline \multirow{2}{*}{ Gene } & \multirow{2}{*}{ vs. } & \multicolumn{2}{|c|}{ Fold-Change } & \multicolumn{2}{|c|}{$p$-Value } & \multirow{2}{*}{ Correlation } \\
\hline & & RNA-Seq & Real-time PCR & RNA-Seq & Real-time PCR & \\
\hline \multirow[t]{3}{*}{ FGF9 } & D12 vs. D18 & 1.01 & 0.89 & 0.9076 & 0.7736 & 0.8825 \\
\hline & D12 vs. D25 & 2.92 & 2.87 & $<0.0001$ & $<0.0001$ & 0.9939 \\
\hline & D18 vs. D25 & 2.82 & 3.32 & 0.0002 & $<0.0001$ & 0.9692 \\
\hline \multirow[t]{3}{*}{$I R F 1$} & D12 vs. D18 & 1.16 & 1.83 & 0.7325 & 0.2655 & 0.9800 \\
\hline & D12 vs. D25 & 5.62 & 7.54 & $<0.0001$ & $<0.0001$ & 0.8467 \\
\hline & D18 vs. D25 & 4.72 & 4.23 & 0.0005 & 0.0136 & 0.9092 \\
\hline \multirow[t]{3}{*}{ OSTN } & D12 vs. D18 & -17.40 & -15.82 & $<0.0001$ & $<0.0001$ & 0.9732 \\
\hline & D12 vs. D25 & -530.57 & -1015.42 & $<0.0001$ & $<0.0001$ & 0.7383 \\
\hline & D18 vs. D25 & -30.93 & -63.69 & 0.0003 & 0.0009 & 0.9799 \\
\hline \multirow[t]{3}{*}{ PTGES } & D12 vs. D18 & -3.45 & -5.37 & $<0.0001$ & $<0.0001$ & 0.9606 \\
\hline & D12 vs. D25 & -4.05 & -13.64 & $<0.0001$ & $<0.0001$ & 0.9807 \\
\hline & D18 vs. D25 & -1.15 & -2.55 & 0.2223 & 0.0912 & 0.9201 \\
\hline \multirow[t]{3}{*}{ S100A9 } & D12 vs. D18 & 610.76 & 329.82 & $<0.0001$ & $<0.0001$ & 0.7967 \\
\hline & D12 vs. D25 & 372.60 & 266.37 & $<0.0001$ & 0.0002 & 0.8823 \\
\hline & D18 vs. D25 & 0.60 & 0.83 & 0.0685 & 0.0502 & 0.9734 \\
\hline \multirow[t]{3}{*}{ STAT1 } & D12 vs. D18 & 0.91 & 0.62 & 0.9542 & 0.3827 & 0.9987 \\
\hline & D12 vs. D25 & 1.98 & 0.87 & 0.0001 & 0.0106 & 0.9336 \\
\hline & D18 vs. D25 & 2.22 & 1.19 & $<0.0001$ & 0.0114 & 0.9725 \\
\hline \multirow[t]{3}{*}{ STC1 } & D12 vs. D18 & 9.40 & 8.39 & $<0.0001$ & $<0.0001$ & 0.9480 \\
\hline & D12 vs. D25 & 51.34 & 38.83 & $<0.0001$ & $<0.0001$ & 0.8834 \\
\hline & D18 vs. D25 & 5.91 & 4.43 & $<0.0001$ & 0.0057 & 0.9508 \\
\hline
\end{tabular}




\section{Discussion}

In pigs, maternal recognition of pregnancy takes place around day 11 and implantation occurs on days $12-26$. In the present study, we collected porcine endometrial tissue samples on day 12 (the time of maternal recognition), day 18 (conceptus attachment), and day 25 (embryo implantation) of pregnancy. To ensure consistency between samples, the myometrium was peeled off. On day 12 of gestation, conceptuses are already elongated but not attached to the uterine wall [17]; the samples of endometrium were taken from the middle portion of each uterine horn and at the antimesometrial side. The endometrial samples on days 18 and 25 of pregnancy were collected from the implantation zones (with the embryo peeled off first) of pregnant gilts.

The RNA-Seq data were analyzed to compare different stages of implantation (days 12, 18, and 25). The results revealed that there are comprehensive transcriptome changes in response to the implantation process. DEGs were highest between days 12 and 25, followed by between days 18 and 25 . The variance in the number of DEGs indicates that the cell activity and gene expression changes in the endometrium were dramatic on day 25 vs. 12. It is mostly likely that the elongating porcine embryos finish their migration through the uterus and start to attach to the luminal epithelium of the endometrium on day 12 [18], while on day 25 the embryo had basically completed the implantation process. As we know, successful implantation requires synchrony between uterus and embryo, and implantation happens during the "implantation window". Periodic expression of many genes important for embryos occurs during implantation. This result agrees with findings from a proteomics study of uterine secretions from days 10 and 13 of the estrous cycle and pregnancy [19,20], in which those authors found more differences in the protein amounts over time than were attributed to pregnancy status.

Transcriptome changes in the porcine endometrium during days 12, 14 [8-10] and days 15-16 [11] have been performed with DNA microarrays or RNA-Seq. These studies have focused on the DEGs between pregnancy and the corresponding day of the estrous cycle (or non-pregnancy), and the periods are mainly in the early stages of implantation (days 12-16). In the present study, we obtained the transcriptome profile of the endometrium in the whole embryo implantation process, and the genes' expression was compared between = early, mid-, and late implantation, respectively. A large number of DEGs were filtered; results indicated that uterine endometrial responses to implantation are complex. In order to achieve a state of endometrial receptivity, a lot of endometrial physiology and cell activities happened in the porcine endometrium during implantation, which is regulated by numerous genes, and the time and space of gene expression is critical for proper embryo-maternal crosstalk and successful embryo implantation. Systematic studies of porcine endometrium are essential for embryo survival and development in early pregnancy.

Early pregnancy is accompanied by many immune reactions simultaneously occurring in the uterus [21,22]. In contrast to day 25 of pregnancy, there is a particularly high overrepresentation of genes associated with the immune response on days 12 and 18, including CD27, CD3D, CD3E, CD3Z, CD40, CD48, CD5, CD6, CD61, CD8A, and ZAP70. In this study, the interesting result is about S100A9, the expression level of which is huge on day 12 of pregnancy, but decreases significantly by days 18 and 25 (Table 5). S100A9 is an inflammatory protein and it exhibits a cytokine-like function, enhancing leukocyte recruitment to the inflammatory site. The expression of S100A9 was associated with early pregnancy loss $[23,24]$. Immune response and cell-adhesion factors expressed in the 
endometrium on days 15-16 ensure proper embryo-maternal crosstalk [11]. The main adhesion factors appear in luminal epithelial cells during the phase of endometrial receptivity [25]. Although the adhesion of the embryos to the endometrium can be regulated at the gene expression level, the global endometrial profile of genes encoding adhesion factors was previously unknown. We found many genes involved in the regulation of cell adhesion in porcine pregnancy, including "Focal adhesion" and the "Cell adhesion molecules (CAMs)" pathway, and for the first time we obtained a complete biological pathway list of upregulated and downregulated genes encoding adhesion molecules in the porcine endometrium during early, mid-, and late implantation (Table 4).

According to the results of KEGG analysis, multiple genes related to the pathway "cytokine-cytokine receptor interaction" were significantly overexpressed in the endometrium on day 18 of gestation vs. days 12 and 25, including CCR7, CSF1R, CXCR3, IL10RA, and IL2RG (Table 3). Its function may be to promote correct communication between the endometrium and the developing conceptus, and to achieve the readiness of uterus for implantation. The uterus has greater receptivity in mid-implantation than in the early and late periods. Many studies indicate that cytokines are important to embryo development and successful implantation. Not only do certain cytokines have completely different effects on implantation-for example, CSF promotes implantation and early development while TNF is deleterious - but the level of the cytokine present is also important. In some cases, absence of a cytokine, for example LIF, is associated with failure of implantation while excess concentrations of a cytokine, for example CSF, can abort an early pregnancy [26-28].

In pigs, fertility rates are generally very high but the early embryonic loss that occurs on days 12-30 of gestation critically affects the potential litter size. Temporal changes that take place in the endometrial environment during the period of early pregnancy in pigs play an important role in embryonic survival and successful pregnancy. Systematic studies of the molecular changes associated with these processes will pave the way for an understanding of endometrial functions and help to increase embryo survival. In the present study, we obtained comprehensive transcriptomic profiles of the porcine endometrium during pregnancy, but one limitation is surely the analysis of endometrium between different implantation stages of pregnancy, not compared with non-pregnancy. This may result in partial genes, which expressed continuously and no significant changes during implantation, were failed to discover. Nevertheless, the gene expression data generated in the present study represent a rich resource for further targeted studies of genes and pathways potentially involved in the regulation of this process.

\section{Conclusions}

The present study identified comprehensive transcriptome changes in the porcine endometrium in early, mid-, and late implantation. Several biological processes and pathways potentially involved in embryo implantation in the early pregnancy of sows were identified by bioinformatics analysis, especially cell proliferation, the regulation of the immune response, the interaction of cytokine receptors, and cell adhesion. This comprehensive identification of transcriptomic changes in the porcine endometrium could be a foundation for targeted studies of genes and pathways that are potentially involved in abnormal endometrial receptivity and embryo loss in early pregnancy. 


\section{Acknowledgments}

This study was supported by the National Natural Science Foundation of China (No. 31201803) and by the Pig Industry Innovation Team of the Modern Agricultural Industrial System of Shandong Province (No. SDAIT-06-022-02). The authors greatly appreciate Shandong Academy of Agricultural Sciences Pig Breeding Farm for collecting samples; Ying Wu, Jiying Wang, and Yin Zhang for technical assistance; and Guifen Liu for thoughtful reading of the manuscript.

\section{Author Contributions}

Haichao Lin designed and performed the experiments and wrote the manuscript; Huaizhong Wang and Yanping Wang provided reagents and reviewed/edited the manuscript; Chang Liu and Cheng Wang performed the experiments; Jianfeng Guo reviewed/edited the manuscript and contributed to discussion.

\section{Conflicts of Interests}

The authors declare no conflict of interest.

\section{References}

1. Morris, D.; Diskin, M. Effect of progesterone on embryo survival. Animal 2008, 2, 1112-1119.

2. Bazer, F.W.; Johnson, G.A. Pig blastocyst-uterine interactions. Differentiation 2014, 87, 52-65.

3. Spencer, T.E.; Johnson, G.A.; Burghardt, R.C.; Bazer, F.W. Progesterone and placental hormone actions on the uterus: Insights from domestic animals. Biol. Reprod. 2004, 71, 2-10.

4. Bazer, F.W.; Thatcher, W.W. Theory of maternal recognition of pregnancy in swine based on estrogen controlled endocrine versus exocrine secretion of prostaglandin F2alpha by the uterine endometrium. Prostaglandins 1977, 14, 397-400.

5. Geisert, R.D.; Renegar, R.H.; Thatcher, W.W.; Roberts, R.M.; Bazer, F.W. Establishment of pregnancy in the pig: I. Interrelationships between preimplantation development of the pig blastocyst and uterine endometrial secretions. Biol. Reprod. 1982, 27, 925-939.

6. Ziecik, A.J.; Waclawik, A.; Kaczmarek, M.M.; Blitek, A.; Jalali, B.M.; Andronowska, A. Mechanisms for the establishment of pregnancy in the pig. Reprod. Domest. Anim. 2011, 46, 31-41.

7. Bazer, F.W.; Thatcher, W.W.; Martinat-Botte, F.; Terqui M. Conceptus development in large white and prolific Chinese Meishan pigs. J. Reprod. Fertil. 1988, 84, 37-42.

8. Østrup, E.; Bauersachs, S.; Blum, H.; Wolf, E.; Hyttel, P. Differential endometrial gene expression in pregnant and nonpregnant sows. Biol. Reprod. 2010, 83, 277-285.

9. Samborski, A.; Graf, A.; Krebs, S.; Kessler, B.; Bauersachs, S. Deep sequencing of the porcine endometrial transcriptome on day 14 of pregnancy. Biol. Reprod. 2013, doi:10.1095/biolreprod.113.107870.

10. Samborski, A.; Graf, A.; Krebs, S.; Kessler, B.; Reichenbach, M.; Reichenbach, H.D.; Ulbrich, S.E.; Bauersachs, S. Transcriptome changes in the porcine endometrium during the preattachment phase. Biol. Reprod. 2013, 89, 1-16. 
11. Franczak, A.; Wojciechowicz, B.; Kotwica, G. Transcriptomic analysis of the porcine endometrium during early pregnancy and the estrous cycle. Reprod. Biol. 2013, 13, 229-237.

12. UCSC Genome Bioinformatics. Swine Genome Sequencing Consortium Sscrofa10.2. Available online: http://genome.ucsc.edu (accessed on 12 January 2015).

13. Huang da, W.; Sherman, B.T.; Lempicki, R.A. Systematic and integrative analysis of large gene lists using DAVID bioinformatics resources. Nat. Protoc. 2008, 4, 44-57.

14. Database for Annotation, Visualization and Integrated Discovery. DAVID Bioinformatics Resources 6.7. Available online: http://david.abcc.ncifcrf.gov (accessed on 18 March 2015).

15. Trapnell, C.; Pachter, L.; Salzberg, S.L. TopHat: Discovering splice junctions with RNA-Seq. Bioinformatics. 2009, 25, 1105-1111.

16. Trapnell, C.; Williams B.A.; Pertea, G.; Mortazavi, A.; Kwan, G.; van Baren, M.J.; Salzberg, S.L.; Wold, B.J.; Pachter, L. Transcript assembly and quantification by RNA-Seq reveals unannotated transcripts and isoform switching during cell differentiation. Nat. Biotechnol. 2010, 28, 511-515.

17. Anderson, L.L. Growth, protein content and distribution of early pig embryos. Anat. Rec. 1978, 190, 143-153.

18. Geisert, R.D.; Schmitt, R.A.M. Early embryonic survival in the pig: Can it be improved? J. Anim. Sci. 2002, 80, 54-65.

19. Kayser, J.P.; Kim, J.G.; Cerny, R.L.; Vallet, J.L. Global characterization of porcine intrauterine proteins during early pregnancy. Reproduction 2006, 131, 379-388.

20. Jalali, B.M.; Bogacki, M.; Dietrich, M.; Likszo, P.; Wasielak, M. Proteomic analysis of porcine endometrial tissue during peri-implantation period reveals altered protein abundance. J. Proteomics 2015, 125, 76-88.

21. Engelhardt, H.; Croy, B.A.; King, G.J. Role of uterine immune cells in early pregnancy in pigs. J. Reprod. Fertil. Suppl. 1997, 52, 115-131.

22. Engelhardt, H.; Croy, B.A.; King, G.J. Conceptus influences the distribution of uterine leukocytes during early porcine pregnancy. Biol. Reprod. 2002, 66, 1875-1880.

23. Passey, R.J.; Williams, E.; Lichanska, A.M.; Wells, C.; Hu, S.; Geczy, C.L.; Little, M.H.; Hume, D.A. A null mutation in the inflammation-associated S100 protein S100A8 causes early resorption of the mouse embryo. J. Immunol. 1999, 163, 2209-2216.

24. Nair, R.R.; Khanna, A.; Singh, K. Role of inflammatory proteins S100A8 and S100A9 in pathophysiology of recurrent early pregnancy loss. Placenta. 2013, 34, 824-827.

25. Bowen, J.A.; Bazer, F.W.; Burghardt, R.C. Spatial and temporal analysis of integrin and Muc-1 expression in porcine uterine epithelium and trophectoderm in vivo. Biol. Reprod. 1996, 55, 1098-1106.

26. Rice, A.; Chard, T. Cytokines in implantation. Cytokine Growth Factor Rev. 1998, 9, 287-296.

27. Dey, S.K.; Lim, H.; Das, S.K.; Reese, J.; Paria, B.C.; Daikoku, T.; Wang, H. Molecular cues to implantation, Endocr. Rev. 2004, 25, 341-373.

28. Spencer, T.E.; Bazer, F.W. Uterine and placental factors regulating conceptus growth in domestic animals. J. Anim. Sci. 2004, 82, 4-13.

(C) 2015 by the authors; licensee MDPI, Basel, Switzerland. This article is an open access article distributed under the terms and conditions of the Creative Commons Attribution license (http://creativecommons.org/licenses/by/4.0/). 